\title{
Boosting the activity of transition metal carbides towards methane activation by nanostructuring ${ }^{\dagger}$
}

\author{
Marc Figueras, ${ }^{\mathrm{a}}$ Ramón A. Gutiérrez, ${ }^{\mathrm{b}, \mathrm{c}, \mathrm{d}}$ Hèctor Prats, ${ }^{\mathrm{a}}$ Francesc Viñes, ${ }^{\mathrm{a}}$ Pedro J. Ramírez, \\ Francesc Illas, ${ }^{\mathrm{a},}{ }^{*}$ and José A. Rodriguez ${ }^{\mathrm{b}, *}$ \\ a Departament de Ciència de Materials i Química Física \& Institut de Química Teòrica i Computacional \\ (IQTCUB), Universitat de Barcelona, Martí i Franquès 1-11, 08028 Barcelona, Spain. \\ ${ }^{b}$ Chemistry Department, Brookhaven National Laboratory, Upton, New York 11973 , \\ United States of America. \\ ${ }^{c}$ Facultad de Ciencias, Universidad Central de Venezuela, Caracas 1020-A, Venezuela. \\ ${ }^{d}$ Present address: Zoneca-CENEX, R\&D Laboratories, Alta Vista, 64770 Monterrey, Mexico
}

\begin{abstract}
The interaction of methane with pristine surfaces of bulk $\mathrm{MoC}$ and $\mathrm{Mo}_{2} \mathrm{C}$ is known to be weak. In contrast, a series of X-ray photoelectron spectroscopy (XPS) experiments, combined with thermal desorption mass spectroscopy (TDS), for $\mathrm{MoC}_{\mathrm{y}}(y=0.5-1.3)$ nanoparticles supported on $\mathrm{Au}(111)$ which is completely inert towards $\mathrm{CH}_{4}$ - show that these systems adsorb and dissociate $\mathrm{CH}_{4}$ at room temperature and low $\mathrm{CH}_{4}$ partial pressure. This industrially-relevant finding has been further investigated with accurate density functional theory (DFT) based calculations on a variety of $\mathrm{MoC}_{\mathrm{y}}$ supported model systems. The DFT calculations reveal that the $\mathrm{MoC}_{\mathrm{y}} / \mathrm{Au}(111)$ systems can feature low $\mathrm{C}-\mathrm{H}$ bond scission energy barriers, smaller than the $\mathrm{CH}_{4}$ adsorption energy. Our theoretical results for bulk surfaces of $\mathrm{Mo}_{2} \mathrm{C}$ and $\mathrm{MoC}$ show that a simple Brøensted-Evans-Polanyi (BEP) relationship holds for $\mathrm{C}-\mathrm{H}$ bond scission on these systems. However, this is not the case for methane activation on the $\mathrm{MoC}_{\mathrm{y}}$ nanoparticles as a consequence of their unique electronic and chemical properties. The discovery that supported molybdenum carbide nanoparticles are able to activate methane at room temperature paves the road towards the design of a new family of active carbide catalysts for methane activation and valorisation, with important implications in climate change mitigation and carbon cycle closure.
\end{abstract}

${ }^{\dagger}$ Electronic supplementary information (ESI) available: S1. C 1s and Mo 3d XPS data for the carbide nanoparticles. S2. Additional computational details. S3. Optimized structures for the transition states of $\mathrm{CH}_{4}$ dissociation on $\mathrm{MoC}_{\mathrm{y}} / \mathrm{Au}(111)$ models. S4. Optimized structures for the transition states of $\mathrm{CH}_{4}$ dissociation on $\delta$-MoC or $\beta-\mathrm{Mo}_{2} \mathrm{C}$ surfaces. See DOI: $x x x x x x x$

*Corresponding authors: José A. Rodriguez (rodriguez@bnl.gov), Francesc Illas (francesc.illas@ub.edu) 


\section{INTRODUCTION}

Natural gas is a common source of energy for heating, cooking, and electricity generation. In this gas, methane $\left(\mathrm{CH}_{4}\right)$ is the major component and its activation and transformation can have a major impact in industrial operations and environmental pollution control, ${ }^{1}$ given that $\mathrm{CH}_{4}$ greenhouse capabilities are $\sim 23$ times larger than those of carbon dioxide $\left(\mathrm{CO}_{2}\right),{ }^{2}$ making $\mathrm{CH}_{4}$ a main role-player of global warming and climate change. Research endeavors have been undertaken to make it possible using $\mathrm{CH}_{4}$ as a $\mathrm{Cl}$ feedstock, an appealing approach for closing the $\mathrm{C}$-cycle ${ }^{3}$ while transforming methane into commodity chemicals such as methanol, ethylene, or benzene. However, the high strength of the $\mathrm{C}-\mathrm{H}$ bonds in $\mathrm{CH}_{4}-4.51 \mathrm{eV} \cdot \mathrm{mol}^{-1}$ for the first bond dissociation energy - and the non-polar character of the molecule make the activation of this hydrocarbon particularly difficult. In this respect, it is well known that the methane monooxygenase enzyme is able to activate methane at room temperature. However, this biological system cannot be used in large-scale industrial-scale operations. ${ }^{4,5}$ Moreover, to avoid the decomposition of the products and competing reactions, methane activation should proceed at low or medium temperatures. ${ }^{4,5}$ These difficulties have triggered a significant amount of research aimed at examining fundamental and practical aspects associated to methane activation by inorganic catalysts, including transition metals, oxides, sulphides, carbides, and zeolites. ${ }^{5-8}$

On late transition metals surfaces, methane binds very weakly and the probability for dissociation is low. ${ }^{6}$ For example, on Ni well-defined surfaces, methane dissociation is significant only at temperatures above $450 \mathrm{~K} ;{ }^{9}$ with similar trends reported for $\mathrm{Pt}$ and $\mathrm{Pd}^{8}$ surfaces. Interestingly, low-coordinated surface sites existing in metallic nanoparticles have been found to achieve $\mathrm{CH}_{4}$ dissociation at or below room temperature even if the ratio of such enhanced activity sites may be too low to lead to large enough conversion. ${ }^{10,11}$ In contrast, a few oxide and metal/oxide systems are able to activate methane at $300 \mathrm{~K}$ or even lower temperatures. ${ }^{12,13}$ On these systems, cooperative interactions between cation and oxide sites are behind the dissociation of the first $\mathrm{C}-\mathrm{H}$ bond in methane with energy barriers below $0.5 \mathrm{eV} .^{12,13,14}$ Transition metal carbides (TMCs) have also been tested as possible catalysts for methane conversion, ${ }^{7,15-18}$ although the most stable extended surfaces of typical TMCs such as MoC and TiC exhibit a very low reactivity towards methane with no evidence of dissociation. ${ }^{7,19}$ Theoretical calculations suggested that metal-terminated metastable surfaces of carbides could be active for the dissociation of methane. ${ }^{19,20}$ However, it is unlikely that such surfaces are exposed when dealing with a bulk TMC under typical reaction conditions although they could well be present in TMC nanoparticles thus representing an interesting possibility. In fact, it is known that TMC nanoparticles supported inside zeolites can catalyse the conversion of methane 
into ethane, benzene and other hydrocarbons. ${ }^{16-18,21}$ In principle, both the structure of the nanoparticle and its carbon/metal ratio could affect its ability to bind and dissociate methane. However, there is no information regarding this point and no systematic study has been reported so far examining the interaction of methane with TMC nanoparticles.

In this article, we use a combination of experimental and theoretical techniques to investigate the reactivity of $\mathrm{MoC}_{\mathrm{y}}$ nanoparticles towards $\mathrm{CH}_{4}$ activation and dissociation. In particular, we focus on molybdenum carbide $\left(\mathrm{MoC}_{\mathrm{y}}\right)$ nanoparticles which are growth on an inert $\mathrm{Au}(111)$ substrate $^{22}$ and employ X-ray photoelectron spectroscopy (XPS), thermal desorption mass spectroscopy (TDS), and density functional theory (DFT) based calculations to examine the interaction of methane with the supported $\mathrm{MoC}_{\mathrm{y}}$ nanoparticles. We provide compelling evidence that the $\mathrm{MoC}_{\mathrm{y}} / \mathrm{Au}(111)$ systems are able to dissociate methane at room temperature. Moreover, for $\mathrm{MoC}_{\mathrm{y}}$ nanoparticles with a carbon/metal ratio of 1 to 1.3 , the $\mathrm{CH}_{\mathrm{x}}$ surface groups generated by the adsorption of methane recombine upon heating to yield ethane and ethylene. Our results for bulk surfaces of $\mathrm{Mo}_{2} \mathrm{C}$ and MoC show that, following the initial ideas of Pallassana and Neurock, ${ }^{23}$ a simple Brøensted-EvansPolanyi (BEP) relationship ${ }^{24,25}$ holds for $\mathrm{C}-\mathrm{H}$ bond scission on these systems. However, this is not the case for methane activation on the $\mathrm{MoC}_{\mathrm{y}}$ nanoparticles as a consequence of their unique electronic and chemical properties.

\section{EXPERIMENTAL DETAILS}

The $\mathrm{MoC}_{\mathrm{y}} / \mathrm{Au}(111)$ systems were prepared following a procedure described in a previous study and established at Brookhaven National Laboratory. ${ }^{22}$ On a $\mathrm{Au}(111)$ substrate, with the characteristic herringbone $(22 \times \sqrt{3})$ reconstruction structure, inverse carbide/gold, sulfide/gold and oxide/gold systems have been generated for fundamental studies in catalysis. ${ }^{22,26-29}$ In this case, the $\mathrm{MoC}_{\mathrm{y}}$ nanoparticles were generated by deposition of Mo metal onto a reactive multilayer of ethylene, which was physisorbed on a $\mathrm{Au}(111)$ surface at $100 \mathrm{~K} .{ }^{22}$ The amount of Mo deposited was estimated using XPS and Mo/Au ratios seen in previous studies for the deposition of Mo on the herringbone structure of $\mathrm{Au}(111) \cdot{ }^{22,30}$ The $\mathrm{Au}(111)$ substrate does not react with ethylene but the deposited Mo does for form carbide nanoparticles. Upon heating to $750 \mathrm{~K}$, the unreacted ethylene desorbed and $\mathrm{MoC}_{\mathrm{y}}$ nanoparticles were left on the gold substrate (Figure S1). This process could be followed using XPS, TDS, and STM. ${ }^{22}$ Following this approach, in XPS measurements, we found no $\mathrm{O} 1 \mathrm{~s}$ signal and $\mathrm{C}$ 1s binding energies which were very different from those of regular hydrocarbons and very close to those reported for molybdenum carbides around 282.5-283 eV (see Figure S1). ${ }^{31-33}$ For the Mo $3 \mathrm{~d}$ core levels, we saw a small shift towards higher binding energy (see 
Figure S2), consistent with previous studies for molybdenum carbides and a $\mathrm{Mo} \rightarrow \mathrm{C}$ charge transfer. $\frac{31,32}{V}$ In this synthetic process, by changing the initial amounts of $\mathrm{Mo}$ and $\mathrm{C}_{2} \mathrm{H}_{4}$ deposited on the $\mathrm{Au}(111)$ substrate, it is possible to control the carbon/molybdenum ratio in the carbide nanoparticles, and this was varied between 0.5 and 1.1. XPS was used to determine this ratio and we utilized as reference previous values measured in our instrument for the $\mathrm{C} 1 \mathrm{~s}$ and Mo $3 \mathrm{~d}$ regions of bulk $\mathrm{MoC}$ and $\mathrm{Mo}_{2} \mathrm{C} .{ }^{34}$ For the bulk sample of $\mathrm{MoC}$, our XPS measurements point to a C/Mo ratio of 0.98-0.96 in good agreement with the ratio typically observed for bulk samples of one-to-one carbides. $^{29,35-37}$. A set of the $\mathrm{MoC}_{\mathrm{y}} / \mathrm{Au}(111)$ surfaces had a C/Mo ratio close to this value but displayed a unique reactivity. Images acquired by scanning tunnelling microscopy (STM) have shown that the $\mathrm{MoC}_{\mathrm{x}}$ nanoparticles are small (0.6-1.5 nm) and aggregate in the face-centred cubic (fcc) troughs located on either side of the elbows of the reconstructed $\mathrm{Au}(111)$ surface. ${ }^{22}$ Previous and current images of STM indicate that the nanoparticles are essentially amorphous and do not have the typical structures of bulk $\mathrm{MoC}$ or $\mathrm{Mo}_{2} \mathrm{C}^{22}$ Thus, due to their size and structure, these nanoparticles can have special chemical and catalytic properties.

The reactivity of the $\mathrm{MoC}_{\mathrm{y}} / \mathrm{Au}(111)$ surfaces towards methane was examined in a system which combines an ultrahigh-vacuum (UHV) chamber (base pressure $\sim 7 \cdot 10^{-10} \mathrm{mbar}$ ) and a batch reactor. ${ }^{38-41}$ Within this system, the sample could be transferred between the reactor and UHV chamber without exposure to air. The UHV chamber was equipped with instrumentation for XPS, ultraviolet photoelectron spectroscopy (UPS), low-energy electron diffraction (LEED), ion scattering spectroscopy (ISS), and TDS. In the tests to study the interactions with methane, clean Au(111) and $\mathrm{MoC}_{\mathrm{y}} / \mathrm{Au}(111)$ surfaces were positioned in the batch reactor at $\sim 300 \mathrm{~K}$, then 1 Torr of $\mathrm{CH}_{4}$ was introduced for a period of five minutes. After this exposure, the $\mathrm{CH}_{4}$ gas was removed and each sample was transferred back to the UHV chamber for surface characterization with XPS and TDS.

\section{COMPUTATIONAL METHODS AND MODELS}

Methane activation on $\mathrm{MoC}_{\mathrm{y}} / \mathrm{Au}(111)$ has been assessed by modelling different $\mathrm{Au}-$ supported $\mathrm{MoC}_{\mathrm{y}}$ nanoparticles with $\mathrm{C} / \mathrm{Mo}$ ratios ranging from 0.67 to 1.50 , as in the experiments, and relying on periodic DFT based calculations. The initial stoichiometric structures of MoC nanoparticles in gas-phase were taken so as to mimic the most stable gas-phase TiC nanoparticles reported in previous work by Lamiel et al., ${ }^{42}$ formerly obtained by data mining searches combining interatomic potentials and DFT calculations. These authors reported a total of nine $\mathrm{Ti}_{6} \mathrm{C}_{6}$ and twelve $\mathrm{Ti}_{12} \mathrm{C}_{12}$ low energy structures. In the present work, these structures were taken as initial guess for the gas-phase $\mathrm{Mo}_{6} \mathrm{C}_{6}$ and $\mathrm{Mo}_{12} \mathrm{C}_{12}$ nanoparticles by simply replacing all Ti atoms by Mo atoms followed 
by full PBE-D3 relaxation without any constraint. Interestingly, for both sizes, the structure of the most stable $\mathrm{MoC}$ isomer corresponds to the most stable one for the $\mathrm{TiC}$ nanoparticle. However, in some cases, the order of stability of the other (i.e., less stable in gas-phase) MoC isomers differs from that of their TiC counterparts. To obtain suitable non-stoichiometric structures in gas-phase, mimicking the composition of the particles in the experiments, a cascade approach was used starting from the two most stable $\mathrm{Mo}_{6} \mathrm{C}_{6}$ and $\mathrm{Mo}_{12} \mathrm{C}_{12}$ structures. The different non-stoichiometric nanoparticles were created removing one of all non-equivalent (Mo or $\mathrm{C}$ ) atoms at a time. This resulted in five $\mathrm{Mo}_{5} \mathrm{C}_{6}$, four $\mathrm{Mo}_{6} \mathrm{C}_{5}$, six $\mathrm{Mo}_{11} \mathrm{C}_{12}$, and other six $\mathrm{Mo}_{12} \mathrm{C}_{11}$ new structures with $\mathrm{C} / \mathrm{Mo}$ ratios between 0.83 to 1.20 . To fill the experimental ratio ranging from 0.5 to 1.3 , structures resulting from successive extractions of one Mo or one $\mathrm{C}$ atom were considered as well. Overall, a full set of 148 gas-phase non-stoichiometric $\mathrm{MoC}_{\mathrm{y}}$ structures were obtained and their structure fully optimized.

The two most stable $\mathrm{Mo}_{6} \mathrm{C}_{6}\left(\mathrm{Mo}_{6} \mathrm{C}_{6}-1\right.$ and $\left.\mathrm{Mo}_{6} \mathrm{C}_{6}-2\right)$ and the most stable $\mathrm{Mo}_{12} \mathrm{C}_{12}$ structures in gas-phase were supported on the $\mathrm{Au}(111)$ surface. This step implied a large number of geometry optimizations due to the high number of possible orientations of the supported nanocluster and the presence of different adsorption sites on the $\mathrm{Au}(111)$ surface. $\mathrm{All} \mathrm{MoC}_{\mathrm{y}} / \mathrm{Au}(111)$ systems were optimized, and the structure presenting the strongest adsorption energy was chosen to perform the study of $\mathrm{CH}_{4}$ adsorption and dissociation, the latter making use of the climbing-image nudged elastic band (CI-NEB) algorithm. Similarly, the most stable non-stoichiometric $\mathrm{Mo}_{6} \mathrm{C}_{5}, \mathrm{Mo}_{6} \mathrm{C}_{4}, \mathrm{Mo}_{4} \mathrm{C}_{6}$, $\mathrm{Mo}_{12} \mathrm{C}_{10}$, and $\mathrm{Mo}_{10} \mathrm{C}_{12}$ structures in gas-phase were supported on $\mathrm{Au}(111)$. Again, for each nonstoichiometric structure, the optimized geometry presenting the strongest adsorption energy was chosen to perform the study of $\mathrm{CH}_{4}$ adsorption and dissociation. In summary, three stoichiometric - two isomers of $\mathrm{Mo}_{6} \mathrm{C}_{6}$ and one of $\mathrm{Mo}_{12} \mathrm{C}_{12}$ - and five non-stoichiometric nanoparticles supported on $\mathrm{Au}(111)$ were investigated, as shown in Figure 1. These carbide nanoparticles have diameters which are within the range of sizes experimentally found with STM for MoCy/Au(111) systems. ${ }^{22}$ For comparison, the extended $\mathrm{C}$ - and Mo-terminated orthorhombic $\beta-\mathrm{Mo}_{2} \mathrm{C}(0001)$ and cubic $\delta$ $\mathrm{MoC}(001)$ surfaces have been studied as well.

All present DFT calculations employed the Perdew-Burke-Ernzerhof (PBE) ${ }^{43}$ exchangecorrelation (xc) functional, known to accurately describe molybdenum carbide and transition metal surfaces. $^{44,45}$ The dispersion - van der Waals, vdW - term was approximated through the D3 correction as proposed by Grimme. ${ }^{46}$ Spin polarization was taken explicitly into account only for the systems containing non-stoichiometric $\mathrm{MoC}_{\mathrm{y}}$ nanoparticles in gas phase as test calculations show that any spin polarization is quenched once the particles are supported on the $\mathrm{Au}(111)$ metallic surface. The transition state (TS) structures for methane dissociation were located using the 
climbing-image nudged-elastic-band (CI-NEB) method $^{47}$ employing five intermediate images, and the gained TS further characterized by appropriate frequency analysis. Initial guesses for those images were generated by means of the atomic simulation environment (ASE) ${ }^{48}$ using the image dependent pair potential (IDPP). ${ }^{49}$ All calculations were carried out using the Vienna ab Initio simulation package (VASP). ${ }^{50}$ Further computational details and obtained geometries are provided in the ESI. Note in passing by that favourable adsorption energies, $E_{a d s}$, are defined negative, and all reported energy values include the zero-point energy (ZPE) term obtained within the harmonic approximation.

\section{RESULTS AND DISCUSSION}

Experiments. Figure 2 shows a C $1 s$ XPS spectrum obtained after exposing clean Au(111) to 1 Torr of methane at $300 \mathrm{~K}$. The noble metal did not react with methane at room or elevated temperatures. This agrees with previous studies which show that this substrate also does not react with ethylene. ${ }^{22}$ At low and high temperatures pure metallic gold is not able to break the $\mathrm{C}-\mathrm{H}$ bonds in the hydrocarbon, even in presence of adsorbed atomic $\mathrm{O} .{ }^{51}$ Included in Figure 2 is a $\mathrm{C} 1 s$ spectrum collected after exposing bulk polycrystalline $\delta$-MoC to 1 Torr of $\mathrm{CH}_{4}$ at $300 \mathrm{~K}$. Only features for the carbon atoms in the carbide are observed. In the region between 284 and $285 \mathrm{eV}$, where signal for $\mathrm{CH}_{\mathrm{x}}$ fragments is usually seen, ${ }^{7}$ no clear features are detected and one sees the plain $\mathrm{C} 1 s$ spectrum of a metal carbide. From previous studies it is known that samples of bulk polycrystalline $\delta$-MoC or TiC do not react with methane at room temperature. ${ }^{7,19}$ The surface metal atoms of such bulk 1:1 TMCs are saturated with $\mathrm{C}$ atoms, and so do not attack the $\mathrm{C}-\mathrm{H}$ bonds in methane, ${ }^{7,19}$

Thus, the blank experiments in Figure 2 show that neither $\mathrm{Au}(111)$ nor bulk $\delta$-MoC is useful for methane activation. In contrast, we found a different behaviour for $\operatorname{MoC}_{\mathrm{y}}(y=0.5-1.3)$ nanoparticles dispersed on $\mathrm{Au}(111)$. These nanoparticles do react with methane at room temperature, and the strength of the interaction appears to be affected by the carbon/metal ratio of the studied system. Figure 3 displays C 1 XPS spectra collected after dosing methane at $300 \mathrm{~K}$ to a $\mathrm{Au}(111)$ surface pre-covered with 0.3 monolayers (ML) of $\mathrm{MoC}_{0.6}$. The fresh sample shows the typical C $1 s$ XPS peak position at $\sim 283 \mathrm{eV}$, expected for a molybdenum carbide. ${ }^{22}$ Upon exposure to methane a second peak appears circa $284.8 \mathrm{eV}$, which cannot be attributed to adsorbed $\mathrm{CH}_{4}$ and indicates the generation of $\mathrm{CH}_{\mathrm{x}}(\mathrm{x}=1,2,3)$ species on top of the carbide surface. ${ }^{7,13,14}$ Annealing to 500 and $600 \mathrm{~K}$ induces the disappearance of the $\mathrm{CH}_{\mathrm{x}}$ features while the features for $\mathrm{MoC}_{\mathrm{y}}$ grow. Figure 4 shows the relative changes in the $\mathrm{CH}_{\mathrm{x}}$ and $\mathrm{MoC}_{\mathrm{y}}$ signals as a function of temperature, and from it one deduces that the $\mathrm{MoC}_{0.6} / \mathrm{Au}(111)$ seems to be metastable in the presence of $\mathrm{CH}_{4}$, and while the Mo attacks the $\mathrm{C}$ atoms in $\mathrm{CH}_{\mathrm{x}}$ the carbon/metal ratio in the carbide appears to increase. A similar behaviour has 
been seen for bulk $\mathrm{Mo}_{2} \mathrm{C}$ in an atmosphere of methane or other hydrocarbons at high temperatures where a $\mathrm{Mo}_{2} \mathrm{C} \rightarrow \mathrm{MoC}$ transformation was seen with in-situ X-ray diffraction for powders of the carbide. ${ }^{52}$ When compared to bulk $\mathrm{Mo}_{2} \mathrm{C}$, our results indicate that the $\mathrm{MoC}_{0.6}$ nanoparticles are more chemically active, as they do react with $\mathrm{CH}_{4}$ at room temperature, although their low stability gives them a limited use as catalysts.

In bulk carbides of molybdenum, an increase in the carbon/metal ratio from 0.5 to 1 leads to a $\mathrm{MoC}$ compound which has a negligible reactivity towards methane, as seen in Figure 2 and in previous studies. ${ }^{7,19}$ In the case of the $\mathrm{MoC}_{\mathrm{y}}$ nanoparticles, the reactivity towards $\mathrm{CH}_{4}$ is also affected by the $\mathrm{C} / \mathrm{Mo}$ ratio, but for these nanostructures, at ratios higher than one, there is still significant reactivity towards methane. Figure 5 shows the C $1 s$ XPS spectra recorded after dosing methane at $300 \mathrm{~K}$ to a $\mathrm{Au}(111)$ surface pre-covered with $0.3 \mathrm{ML}$ of $\mathrm{MoC}_{1.1}$. The fresh sample shows again the typical $\mathrm{C} 1 s$ features for a carbide near $\sim 283 \mathrm{eV},{ }^{22}$ and the dosing of methane leads to the appearance as well of a second peak near $284.5 \mathrm{eV}$ due to adsorbed $\mathrm{CH}_{\mathrm{x}}$. Thus, when going from Cmeagre to $\mathrm{C}$-rich nanoparticles $-\mathrm{MoC}_{0.6}$ to $\mathrm{MoC}_{1.1}$ - the system is still able to dissociate methane at room temperature, although the adsorbed $\mathrm{CH}_{\mathrm{x}}$ binding weakens, since, as shown in Figures 5 and 6 , a minor temperature increase triggers a rapid decrease in the $\mathrm{CH}_{\mathrm{x}}$ signal intensity without, however, significantly affecting the $\mathrm{C} 1 \mathrm{~s}$ signal intensity assigned to the $\mathrm{MoC}_{\mathrm{y}}$ carbide. Therefore, the $\mathrm{MoC}_{1.1}$ nanoparticles appear to be stable under an atmosphere of methane. This behaviour is reminiscent of that observed for MoC powders ${ }^{30}$ and bulk crystals of 1:1 TMCs. $^{5}$ Indeed, we found that the $\mathrm{MoC}_{1.1} / \mathrm{Au}(111)$ system was able to sustain many $\mathrm{CH}_{4}$ adsorption/desorption cycles without any significant change neither on the $\mathrm{C} / \mathrm{Mo}$ ratio nor in the reactivity of the surface towards $\mathrm{CH}_{4}($ Figure 7). Thus, in the $\mathrm{MoC}_{1.1}$ nanoparticles, one has the right balance of stability and activity making them useful as catalysts.

As far as the chemical behaviour of adsorbed $\mathrm{CH}_{\mathrm{x}}$ is concerned, mass spectrometer signals detected mainly the evolution of $\mathrm{CH}_{4}$ from the $\mathrm{CH}_{\mathrm{x}} / \mathrm{MoC}_{1.1} / \mathrm{Au}(111)$ surface, as a consequence of a $\mathrm{CH}_{\mathrm{x} \text {,ads }}+(4-\mathrm{x}) \cdot \mathrm{H}_{\mathrm{ads}} \rightarrow \mathrm{CH}_{4, \text { gas }}$ recombination, but with noticeable signals for $\mathrm{C}_{2} \mathrm{H}_{6}$ and $\mathrm{C}_{2} \mathrm{H}_{4}$, see Figure 8. No CO or water desorption was found, consistent with a lack of an O 1s XPS signal after preparing the carbide overlayer or after dosing methane. In average, the relative amount of the desorbed hydrocarbons from the $\mathrm{CH}_{\mathrm{x}} / \mathrm{MoC}_{1.1} / \mathrm{Au}(111)$ surface was methane (79\%), ethane (15\%), and ethylene (7\%). Thus, it is clear that the species produced by the $\mathrm{CH}_{4}$ dissociation are chemically active and so susceptible to be used for producing other, more complex hydrocarbons. Indeed, one can envision that nanoparticles of the $\mathrm{MoC}_{1.1}$ type could be responsible for the activity seen over $\mathrm{MoC}_{\mathrm{x}} / \mathrm{ZSM}-5$ catalysts when transforming methane into larger hydrocarbons. ${ }^{16-18,21}$ 
Computational study. To disclose the chemistry behind the described experiments for the $\mathrm{MoC}_{\mathrm{x}} / \mathrm{Au}(111)$ systems, methane adsorption and first $\mathrm{C}-\mathrm{H}$ bond scission have been studied on eight different supported $\mathrm{MoC}_{\mathrm{y}}$ nanoparticles with $\mathrm{C} / \mathrm{Mo}$ ratios ranging from 0.67 to 1.50 , as in the experiments. For comparison, similar calculations have been carried for the extended C- and Moterminated $\beta-\mathrm{Mo}_{2} \mathrm{C}(0001)$ and $\delta$-MoC(001) surfaces. The interaction of all the above stated nanoparticles with the $\mathrm{Au}(111)$ surface has been studied by explicitly and systematically placing the $\mathrm{MoC}_{\mathrm{y}}$ center of mass above several non-equivalent sites (i.e., top, bridge, and hollow sites) and exploring several orientations per site as described in the section on Computational Methods and Models. A similar procedure has been used to explore the structure of $\mathrm{CH}_{4}, \mathrm{CH}_{3}$, and $\mathrm{H}$ moieties when adsorbed on the supported clusters, where $\eta^{1}, \eta^{2}$, and $\eta^{3}$ connectivities have been considered for $\mathrm{CH}_{4}{ }^{19}$

The present calculations show that, in general, $\mathrm{CH}_{4}$ prefers to adsorb on low-coordinated Mo atoms with $\eta^{2}$ connectivity, see Figure 9, featuring surprisingly high adsorption energies, ranging from -0.38 to $-1.16 \mathrm{eV}$, see PBE-D3 $E_{a d s}$ values listed in Table 1, thus suggesting a clear meeting point in between the Mo special affinity towards $\mathrm{CH}_{4}$ and the low-coordination effect. ${ }^{10,19}$ Clearly, the $\mathrm{MoC}_{\mathrm{y}}$ nanoparticles exhibit $E_{a d s}$ values larger than the extended surface, which range from -0.17 to $-0.39 \mathrm{eV}$ only — see the optimized geometries in Figure 10. Similarly, $\mathrm{CH}_{3}$ species also prefer low-coordinated Mo atoms, which agrees with the experimental finding that C-poor $\mathrm{MoC}_{\mathrm{y}}$ nanoparticles present a stronger binding towards $\mathrm{CH}_{\mathrm{x}}$ species. Finally, atomic $\mathrm{H}$ can be adsorbed indistinguishably at both top-C or top-Mo sites. Note also that, since the removing one carbon atom does not produce a significant structural reconstruction, the most stable $\mathrm{Mo}_{6} \mathrm{C}_{6}$ isomer $\left(\mathrm{Mo}_{6} \mathrm{C}_{6}-1\right)$ and $\mathrm{Mo}_{6} \mathrm{C}_{5}$ structures are actually very similar, see Figure 1 . The $\mathrm{CH}_{4}$ adsorption and subsequent dissociation in the latter structure has been studied by considering the most stable adsorption site near the $\mathrm{C}$ vacancy defect. The same strategy has been used on the $\mathrm{Mo}_{10} \mathrm{C}_{12}$ structure, since it is very similar to $\mathrm{Mo}_{12} \mathrm{C}_{12}$, except near the Mo vacancy defect.

For the eight selected supported $\mathrm{MoC}_{\mathrm{y}}$ structures, as well as for the above mentioned extended $\delta$-MoC and $\beta-\mathrm{Mo}_{2} \mathrm{C}$ surfaces, we have carried out TS searches for $\mathrm{CH}_{4}$ dissociation by using the CI-NEB method. Specifically, the dissociation of an adsorbed $\mathrm{CH}_{4}$ molecule from its most stable adsorption site to produce $\mathrm{CH}_{3}$, typically remaining in the same site, and one atomic $\mathrm{H}$ typically ended adsorbed in the most stable nearby site, has been studied. Note that, for every structure, several dissociation energy paths - between 3 to 7 depending on the chosen structurehave been explored with different final configurations, so as to have a clear, unequivocal description 
of the $\mathrm{CH}_{4}$ dissociation energy landscape. The optimized geometries for all obtained TSs are reported in Figures S3 and S4 of the ESI. The energy barriers values, reported in Table 1, are thus the lowest among the explored energy paths. Regarding the C-terminated $\beta-\mathrm{Mo}_{2} \mathrm{C}(0001)$ and $\delta$-MoC (001) extended surfaces, the $\mathrm{CH}_{4}$ adsorption energy is always much smaller than the energy barrier for dissociation, in agreement with experimental findings that these surfaces do not dissociate methane, and implying a preference for desorption rather than for dissociation. In the case of the Moterminated $\beta-\mathrm{Mo}_{2} \mathrm{C}(0001)$ surface, the energy barrier is circa $0.1 \mathrm{eV}$ larger that the adsorption energy, indicating that this particular surface may exhibit some activity towards methane, also in agreement with experiments. However, most of the studied $\mathrm{MoC}_{\mathrm{y}} / \mathrm{Au}(111)$ systems feature energy barriers for dissociation equal or lower than the adsorption energy of methane, with the only exceptions of $\mathrm{Mo}_{4} \mathrm{C}_{6}$ and $\mathrm{Mo}_{10} \mathrm{C}_{12}$, suggesting that $\mathrm{MoC}_{\mathrm{y}}$ nanoparticles with $y>1.2$ present a lower activity compared to other nanoparticles.

The analysis of DFT results also permits to identify the nanocluster size effect on the $\mathrm{CH}_{4}$ dissociation energy barrier, i.e. by comparing results for most stable $\mathrm{Mo}_{6} \mathrm{C}_{6}$ and $\mathrm{Mo}_{12} \mathrm{C}_{12}$ structures. For both supported clusters, the energy barriers for $\mathrm{CH}_{4}$ dissociation are quite similar, 0.58 and 0.60 $\mathrm{eV}$, respectively. Consequently, the effect of nanoparticle size may not be significant, at least for stoichiometric structures, although, obviously, this preliminary statement would be confirmed when data for larger nanoparticles could be acquired. Nevertheless, the present results indicate that the effect of the nanocluster shape seems to play a dominant role. Take, for instance, the supported $\mathrm{Mo}_{6} \mathrm{C}_{6}$ nanoparticles, where the methane dissociation energy barriers for the most stable $\left(\mathrm{Mo}_{6} \mathrm{C}_{6}-1\right)$ and second most stable $\left(\mathrm{Mo}_{6} \mathrm{C}_{6}-2\right)$ supported structures are 0.58 and $1.02 \mathrm{eV}$, respectively. Clearly, the large difference in the calculated energy barriers is to be attributed to the large structural difference which is clearly seen in Figure 1. Finally, the results reported in Table 1 suggest that the $\mathrm{C}-\mathrm{H}$ scission energy barrier on Mo-deficient systems is very similar to their stoichiometric homologs. The case of C-meagre systems is especially interesting since feature much lower energy barriers which may be as low as $0.08 \mathrm{eV}$ for $\mathrm{Mo}_{6} \mathrm{C}_{4}$, an exceptional result that perfectly agrees with the experimental observation that $\mathrm{MoC}_{0.6}$ nanoparticles are the most reactive ones.

Unravelling trends for $\mathrm{C}-\mathrm{H}$ bond activation on bulk surfaces and nanostructures of molybdenum carbides. To further investigate key points in the activation of the $\mathrm{C}-\mathrm{H}$ bond in $\mathrm{CH}_{4}$ on different systems of molybdenum carbide we investigated trends for the adsorption and dissociation of the hydrocarbon on the bulk surfaces and nanostructures examined. In a past study a clear correlation was found when comparing $\mathrm{E}_{\mathrm{b}}$ for $\mathrm{CH}_{4}$ dissociation vs. $\mathrm{E}_{\text {reac }}$ (i.e., BEP relationship) on $\mathrm{Ni} / \mathrm{TiC}(001)$ systems and on bare Ni(111). ${ }^{7}$ Figure 11 shows that this type of correlation holds well comparing the results for the adsorption and dissociation of methane on the bulk surfaces of $\delta$ - 
$\mathrm{MoC}$ and $\beta-\mathrm{Mo}_{2} \mathrm{C}$ (the latter with two possible terminations). However, for the nanoparticles there are deviations of the linearity which are a strong indication of a different underlying chemistry. The results in Figure 11 indicate that the reactivity of the finite nanoparticles cannot be extrapolated from the behavior seen for the extended bulk carbides. In general, the breakdown of the correlation is mainly a consequence of a lowering in the energy barrier for the $\mathrm{CH}_{4} \rightarrow \mathrm{CH}_{3}+\mathrm{H}$ dissociation on the carbide nanoparticles, while keeping similar reaction energies to those for extended carbides. As discussed above, this lowering is a consequence of the existence of special low-coordinated Mo atoms in the vertices of the nanostructures. The energy barriers for methane dissociation on the most active $\mathrm{MoC}_{\mathrm{y}}$ nanoparticles are close to those calculated on $\mathrm{IrO}_{2}(110)$ and $\mathrm{Ni} / \mathrm{CeO}_{2}(111)$ surfaces. ${ }^{12,13}$ On those systems, a concerted mechanism has been reported for low-temperature activation where the cleavage of the first $\mathrm{C}-\mathrm{H}$ bond in methane involves simultaneous bonding interactions with a metal cation and an oxygen anion. ${ }^{12,13}$ This type of dissociative interaction cannot take place on the $\mathrm{MoC}_{\mathrm{y}}$ nanoparticles where the $\mathrm{C}$ centers do not have the very high negative charge present in the $\mathrm{O}$ centers of an oxide. Nevertheless, the $\eta^{2}$ connectivity on Mo atoms seen in Figure 9 is very efficient for the activation of methane. Such a type of dissociative interaction probably occurs when nanoparticles of $\mathrm{MoC}_{\mathrm{y}}$ are dispersed in the cages of zeolites and methane is transformed into ethane, benzene and other hydrocarbons. ${ }^{16-18,21}$

\section{CONCLUSIONS}

The present experimental and theoretical results point to a clear enhancement in the reactivity of the $\mathrm{MoC}$ based systems towards methane activation when going from extended surfaces to the case of $\mathrm{MoC}_{\mathrm{y}}(y=0.5-1.3)$ nanoparticles supported on $\mathrm{Au}(111)$. The supported $\mathrm{MoC}_{\mathrm{y}}$ nanoparticles are able to dissociate $\mathrm{CH}_{4}$ at room temperature, and the activity, the stability, and the strength of the interaction with $\mathrm{CH}_{\mathrm{x}}$ species appears to depend on the $\mathrm{C} / \mathrm{Mo}$ ratio. While $\mathrm{C}$ - deficient nanoparticles are very reactive, they feature low stability due to the strong binding of the adsorbed $\mathrm{CH}_{\mathrm{x}}$ species, which leads to an increase in the $\mathrm{C} / \mathrm{Mo}$ ratio upon annealing. On the other hand, Mo-deficient systems present the right balance of stability and activity. Although, Mo-deficient nanoparticles are less reactive, they are still able to dissociate methane at room temperature, and are stable under an atmosphere of methane, posing themselves as attractive catalytic systems towards $\mathrm{CH}_{4}$ capture and catalytic conversion.

The present exciting and technologically relevant experimental result were explained by means of DFT based calculations on a broad enough set of supported $\mathrm{MoC}_{\mathrm{y}}$ nanoparticles models with $\mathrm{C} / \mathrm{Mo}$ ratios ranging from 0.67 to 1.50 . The DFT calculations confirm that supported carbide 
nanoparticles feature stronger $\mathrm{CH}_{4}$ adsorption energies than extended $\delta$-MoC or $\beta-\mathrm{Mo}_{2} \mathrm{C}$ surfaces, with adsorption energy values up to $-1.16 \mathrm{eV}$. Moreover, the energy barrier for $\mathrm{CH}_{4}$ dissociation on the nanoparticles gets substantially reduced, and can be as low as $0.08 \mathrm{eV}$ for C-deficient systems, perfectly agreeing with the experimental findings. All in all, the present results open the way for the preparation of a new family of active catalysts for methane activation and conversion under mild conditions, thus widening the applications of existing natural gas resources.

\section{CONFLICTS OF INTEREST}

The authors declare no conflict of interest. 


\section{ACKNOWLEDGEMENTS}

This manuscript has been authored by employees of Brookhaven Science Associates, with the financial support of the Office of Basic Energy Sciences in the U.S. Department of Energy under Contract No. DE-SC0012704. The work carried out at University of Barcelona has been supported by the MICIUN RTI2018-095460-B-I00 research grants and by the Spanish Structures of Excellence Maria de Maeztu program through grant MDM-2017-0767. The authors are also grateful to Generalitat de Catalunya for partial support through grants 2017 SGR13 and XRQTC. F.I. acknowledges additional support from the 2015 ICREA Academia Award for Excellence in University Research. F.V. is thankful to Ministerio de Economía y Competitividad (MED) for his Ramón y Cajal (RYC-2012-10129) research contract. Authors are thankful for the computational time provided at Marenostrum-IV supercomputer at the Barcelona Supercomputing Centre (BSC) through the grants QCM-2019-1-0008 and QCM-2018-3-0010 awarded by the Red Española de Supercomputacion (RES). 
Figure 1. Optimized geometries (top and side views) for the studied $\mathrm{MoC}_{\mathrm{y}} / \mathrm{Au}(111)$ systems. $\mathrm{Au}$, Mo, $\mathrm{C}$, and $\mathrm{H}$ atoms are shown as yellow, blue, black, and white spheres, respectively. In all cases, the most stable isomer has been studied, except for the $\mathrm{Mo}_{6} \mathrm{C}_{6}$, where the second most table structure was also studied $\left(\mathrm{Mo}_{6} \mathrm{C}_{6}-2\right)$.

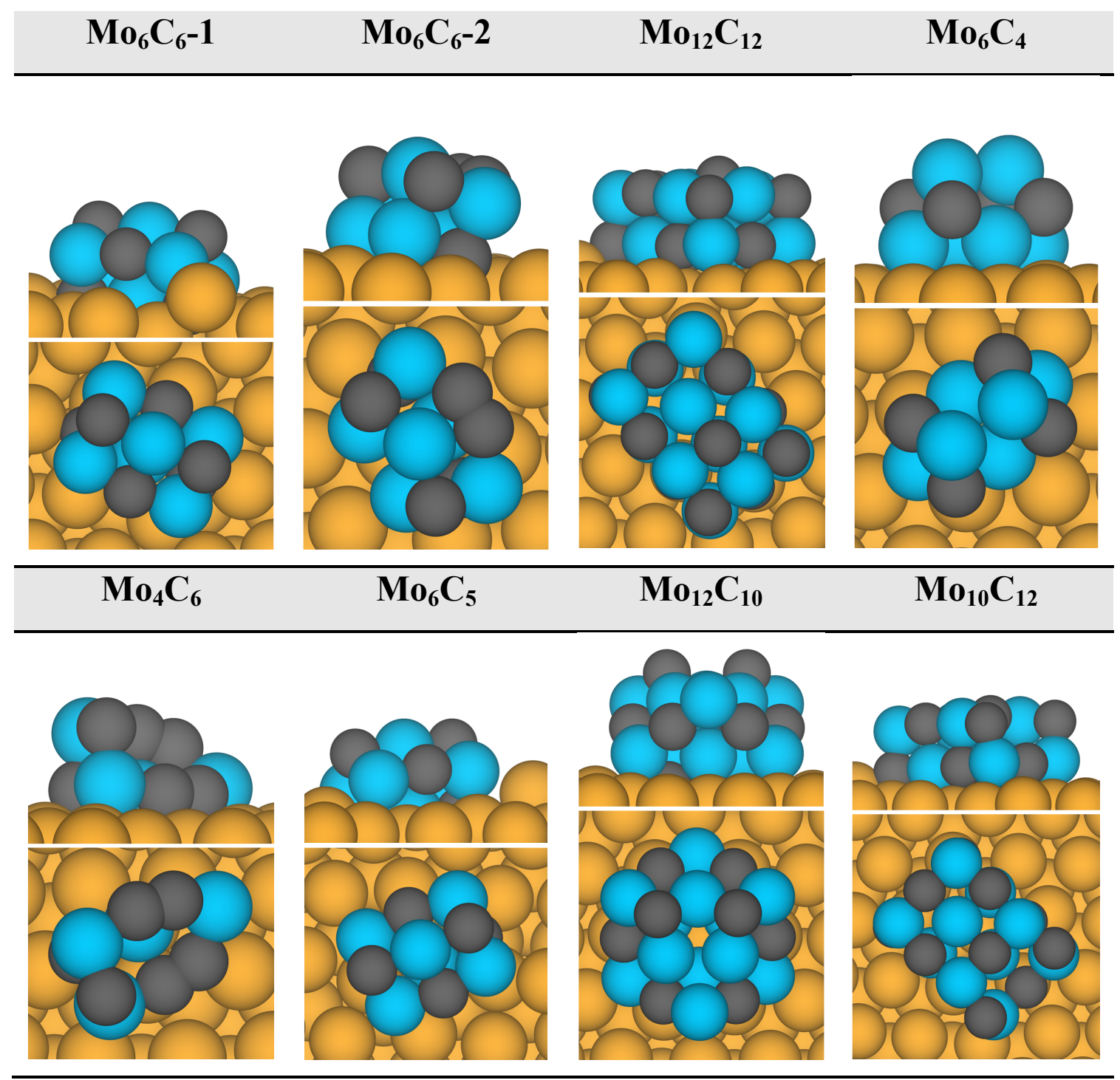


Figure 2. C $1 s$ XPS spectra collected after dosing methane to clean Au(111) and bulk polycrystalline $\delta$-MoC. The dosage of methane was 1 Torr for 5 minutes.

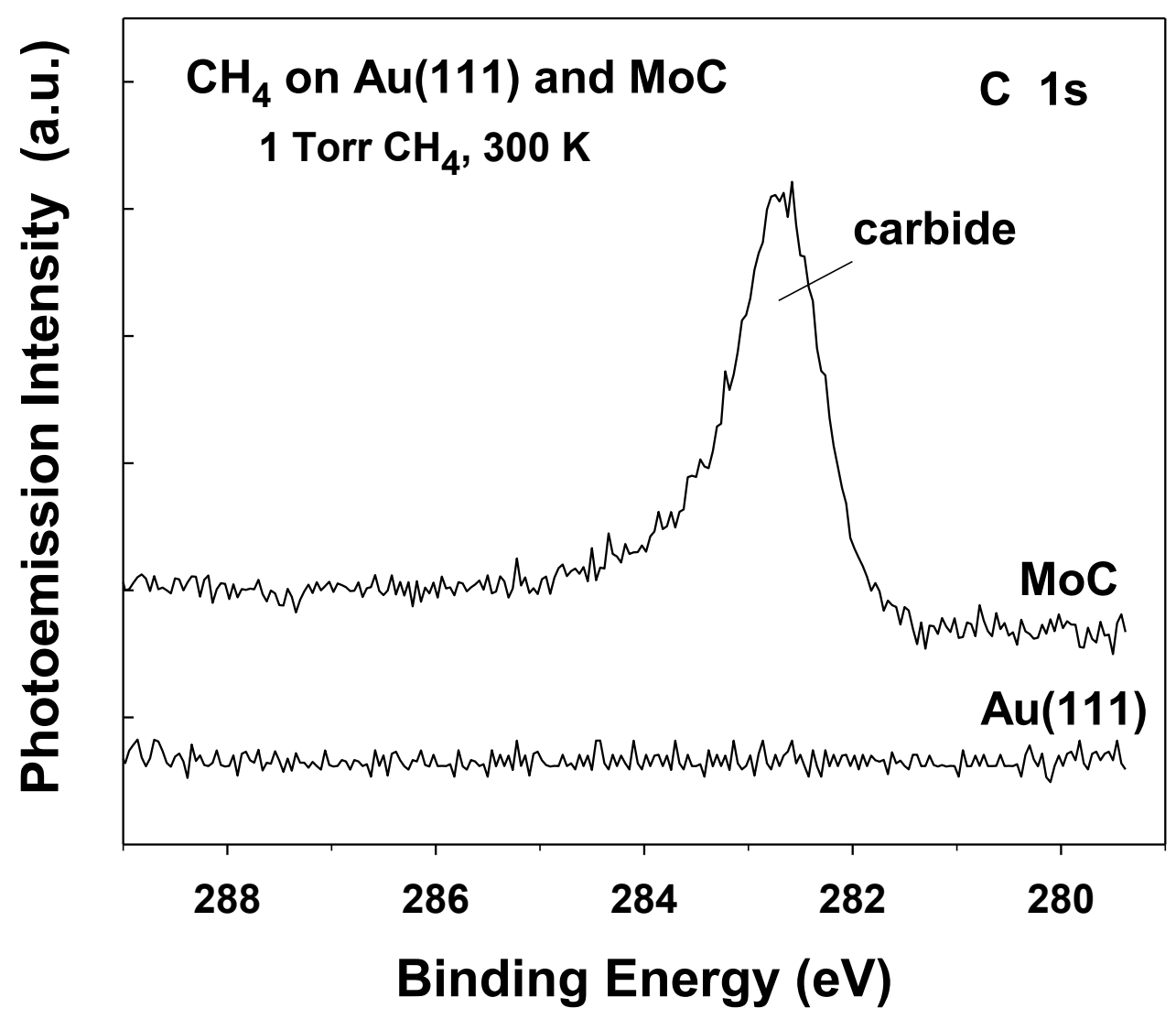


Figure 3. C $1 s$ XPS spectra collected before and after dosing methane to $\mathrm{MoC}_{0.6} / \mathrm{Au}(111)$ at $300 \mathrm{~K}$. This was followed by heating to 400,500 , and $600 \mathrm{~K}$. The dosage of methane was 1 Torr for 5 minutes. The initial coverage of $\mathrm{MoC}_{0.6}$ on the $\mathrm{Au}(111)$ substrate was $0.3 \mathrm{ML}$.

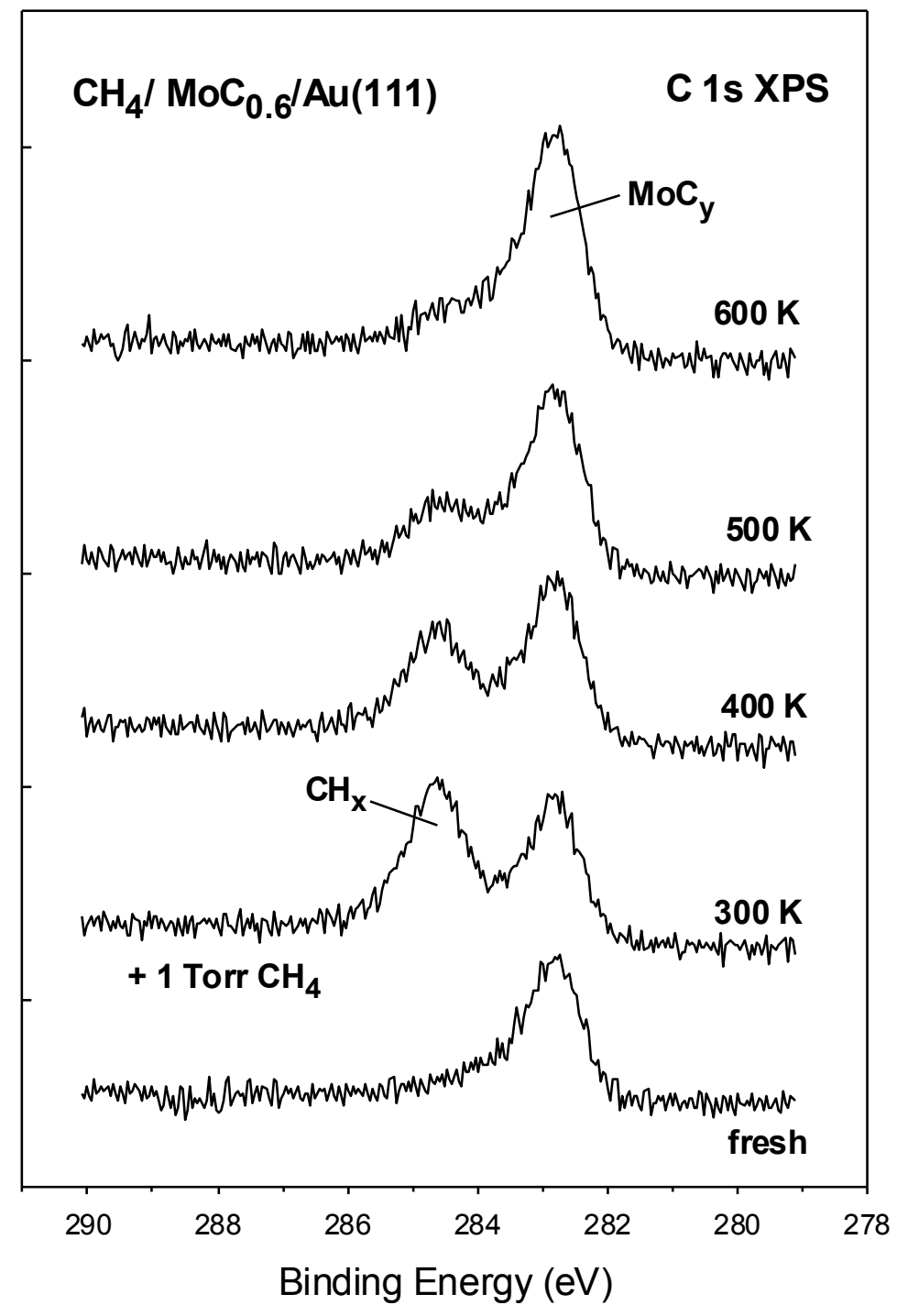


Figure 4. Variation of the $\mathrm{CH}_{\mathrm{x}}$ and $\mathrm{MoC}_{\mathrm{y}}$ intensities as a function of temperature in $\mathrm{CH}_{4} / \mathrm{MoC}_{0.6} / \mathrm{Au}(111)$. Initially the surface was exposed to 1 Torr of methane for 5 minutes at $300 \mathrm{~K}$, see Figure 1.

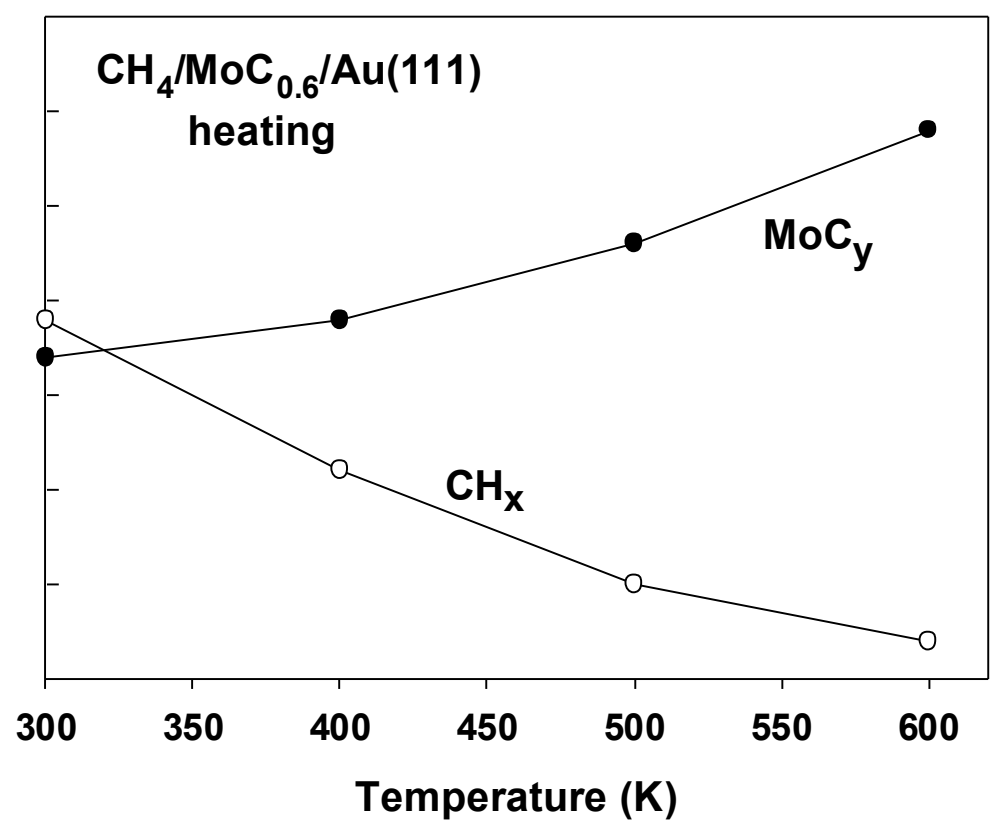


Figure 5. C $1 s$ XPS spectra collected before and after dosing methane to $\mathrm{MoC}_{1.1} / \mathrm{Au}(111)$ at $300 \mathrm{~K}$. This was followed by heating to $350,400,450$, and $500 \mathrm{~K}$. The dosage of methane was 1 Torr for 5 minutes. The initial coverage of $\mathrm{MoC}_{1.1}$ on the $\mathrm{Au}(111)$ substrate was $0.3 \mathrm{ML}$.

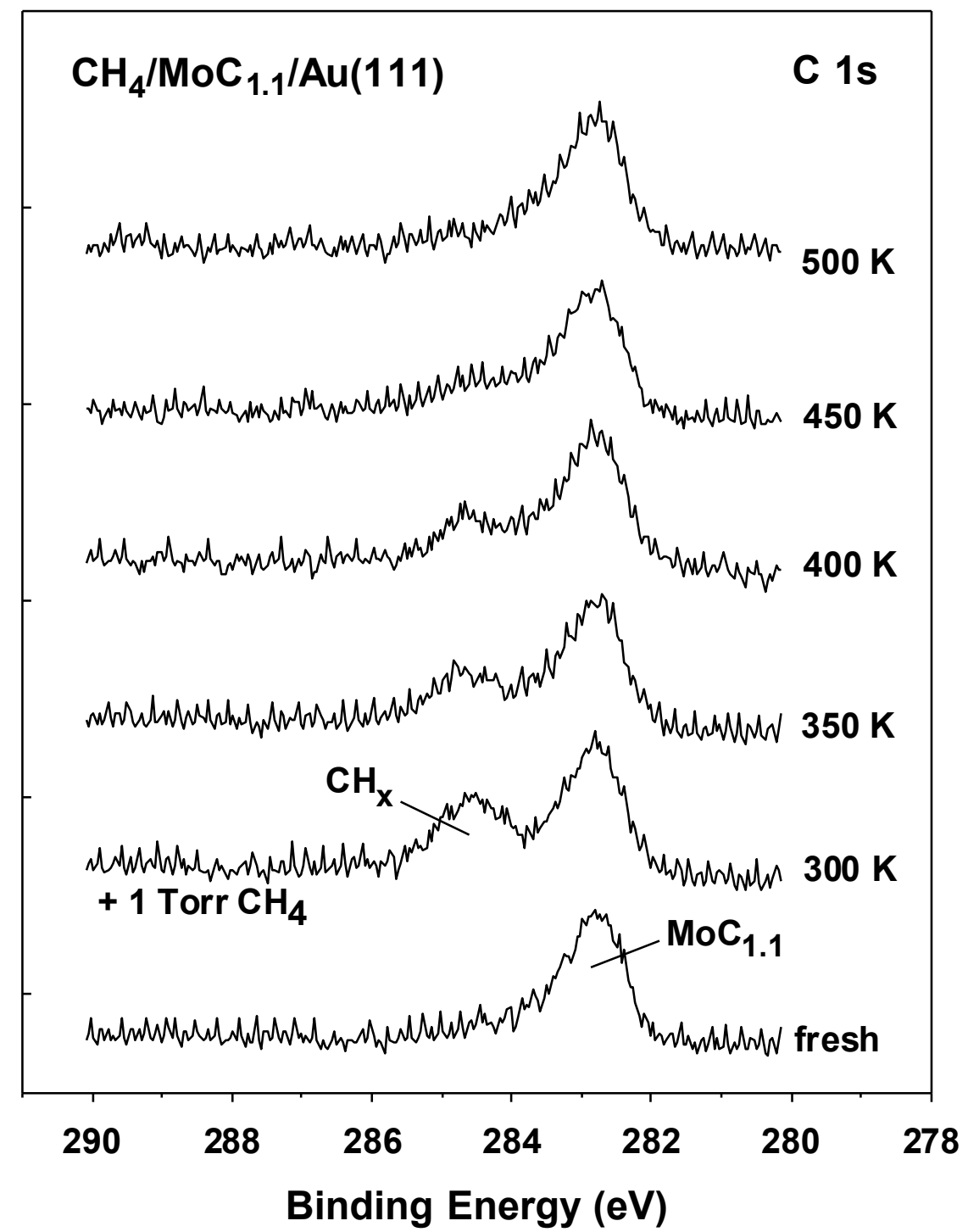


Figure 6. Variation of the $\mathrm{CH}_{\mathrm{x}}$ and $\mathrm{MoC}_{\mathrm{y}}$ intensities as a function of temperature in $\mathrm{CH}_{4} / \mathrm{MoC}_{1.1} / \mathrm{Au}(111)$. Initially the surface was exposed to 1 Torr of methane for 5 minutes at $300 \mathrm{~K}$, see Figure 3.

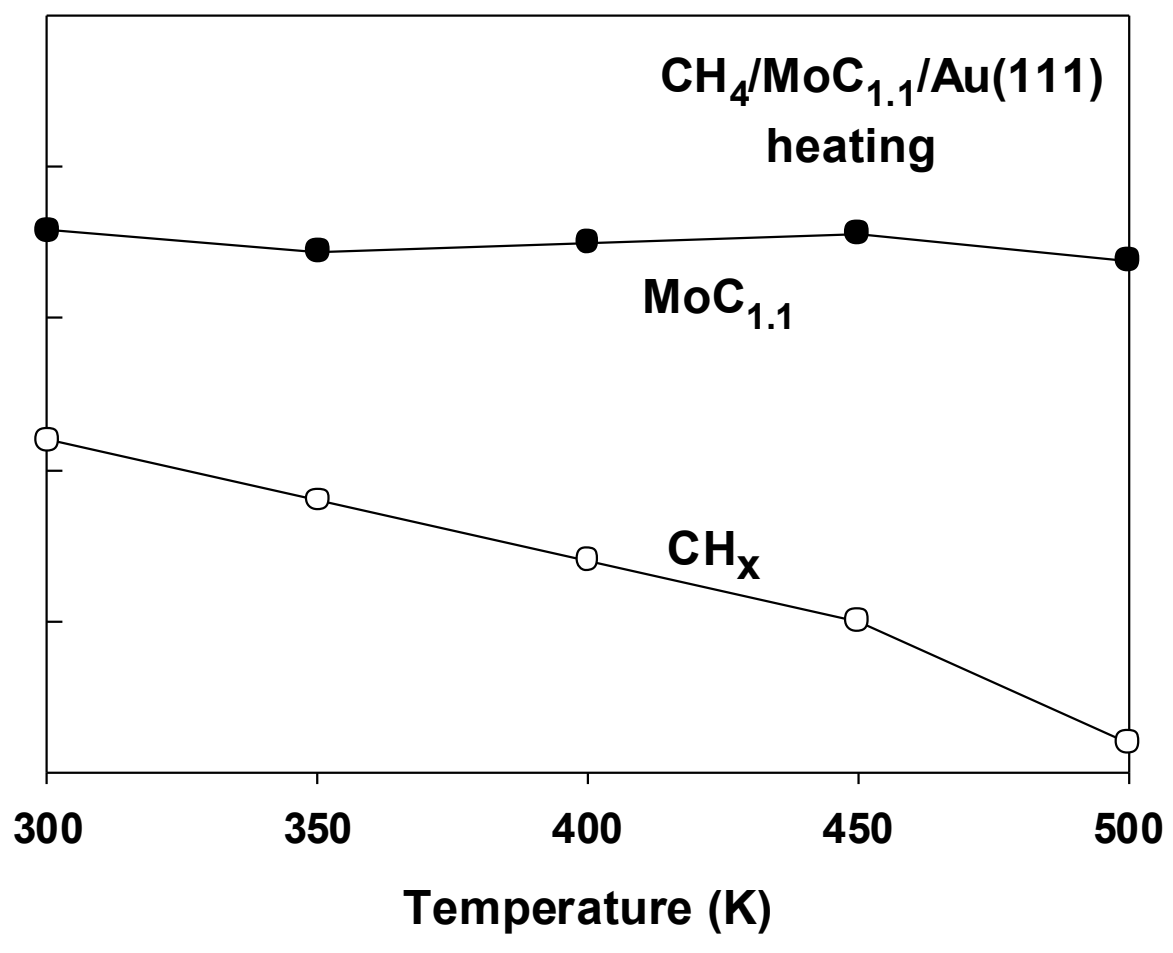


Figure 7. Top panel: C $1 s$ XPS spectra collected after 1 and 5 cycles of adsorption/desorption for the $\mathrm{CH}_{4} / \mathrm{MoC}_{1.1} / \mathrm{Au}(111)$ at $300 \mathrm{~K}$. In each cycle, the surface was exposed to 1 Torr of $\mathrm{CH}_{4}$ at $300 \mathrm{~K}$ for five minutes. Then, the gas was removed, the corresponding C $1 s$ XPS spectrum was recorded, and finally the sample was heated to $500 \mathrm{~K}$ to desorb the $\mathrm{CH}_{\mathrm{x}}$ deposited before the beginning of the next cycle. This was repeated for five cycles. Bottom: Amount of $\mathrm{CH}_{\mathrm{x}}$ adsorbed in each cycle after dosing methane at $300 \mathrm{~K}$. The initial coverage of $\mathrm{MoC}_{1.1}$ on the $\mathrm{Au}(111)$ substrate was $0.3 \mathrm{ML}$ and essentially remained constant after five cycles.
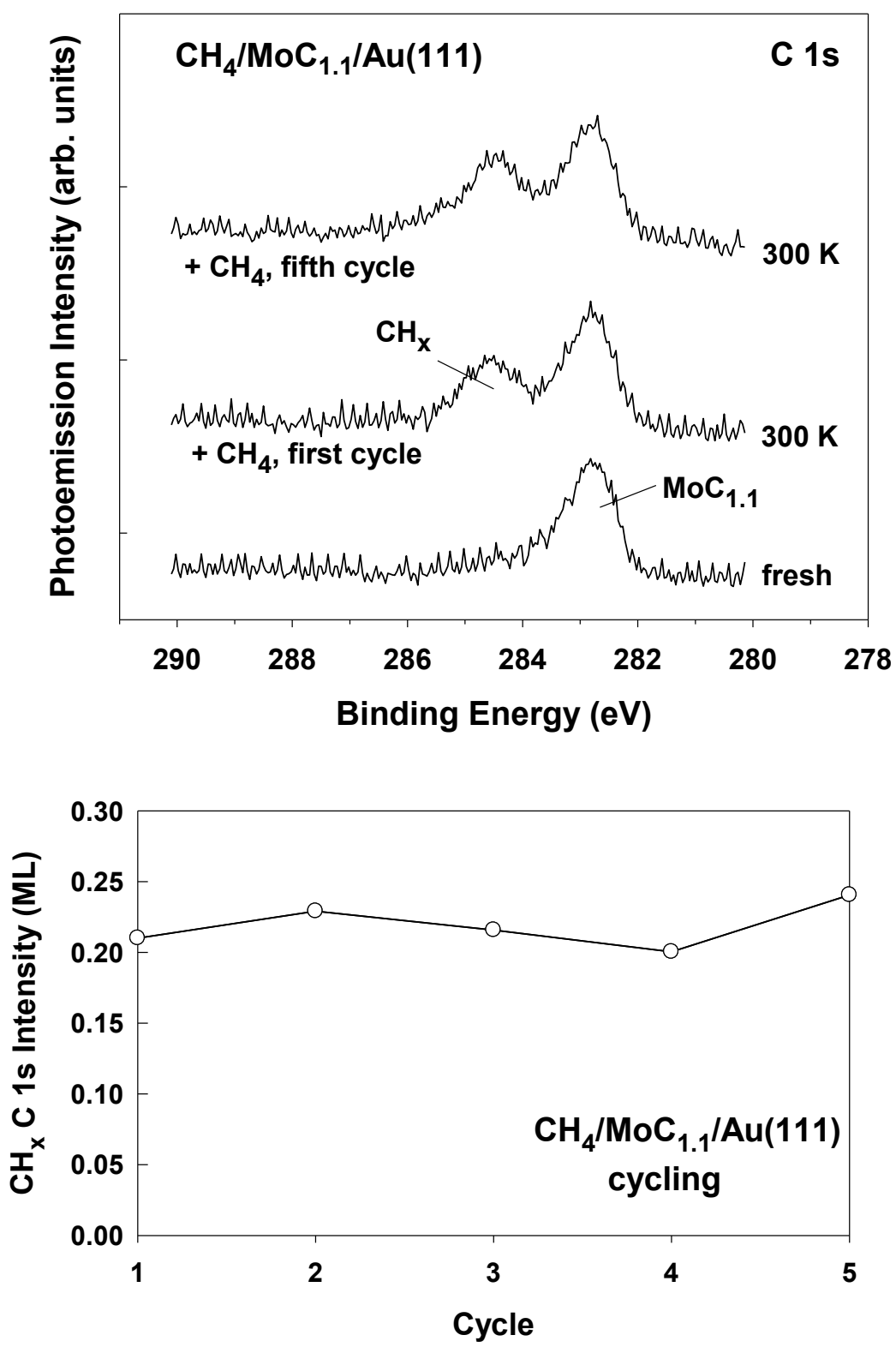
Figure 8. Thermal desorption spectra collected after exposing a $\mathrm{MoC}_{1.1} / \mathrm{Au}(111)$ surface to 1 Torr of methane for 5 minutes at $300 \mathrm{~K}$ in a micro-reactor. The gas was pumped out and the sample was transferred to a UHV chamber for a TDS study (heating ramp $2 \mathrm{~K} / \mathrm{s}$ ).

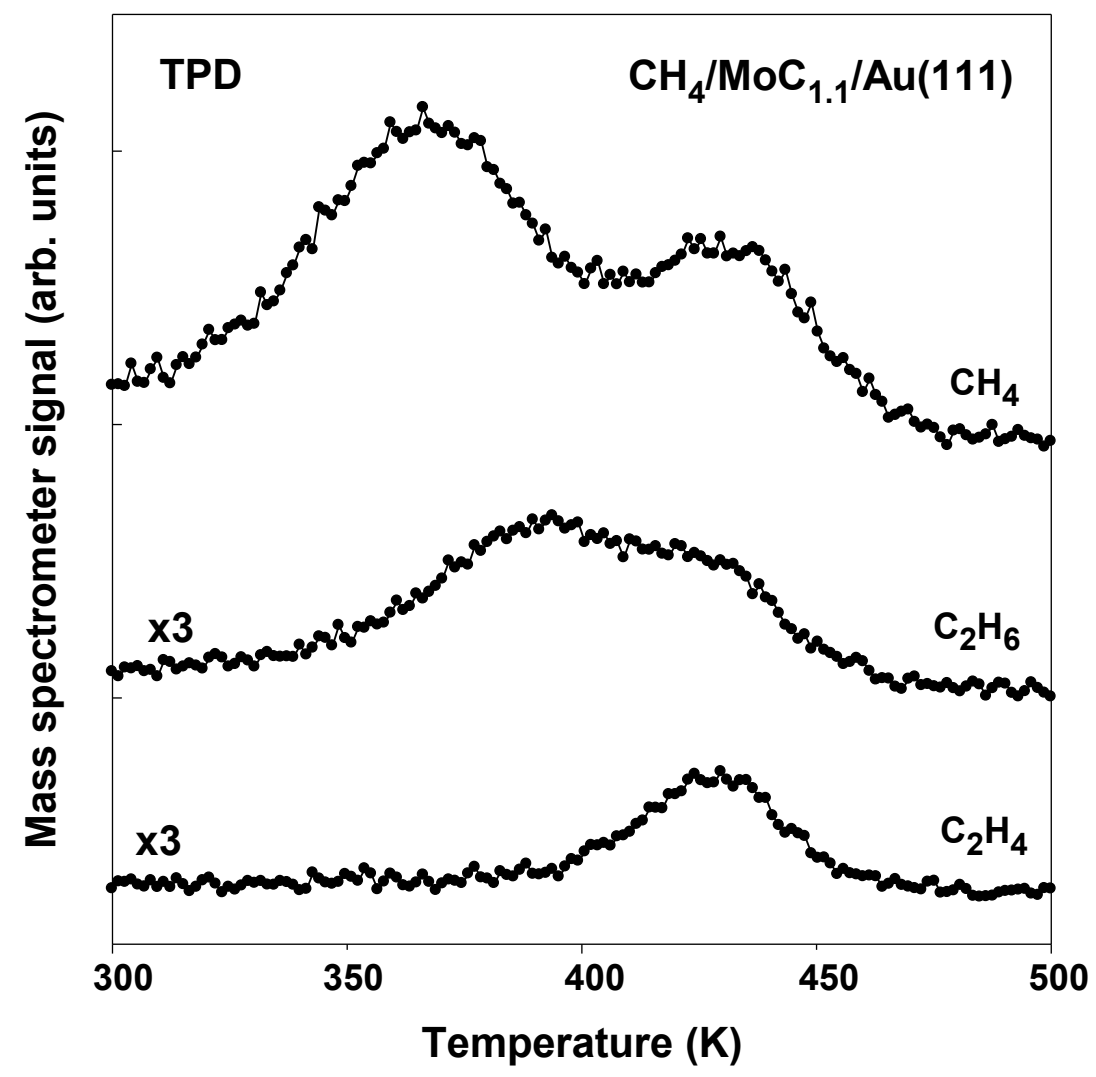


Figure 9. Optimized geometries (top and side views) for the adsorption of $\mathrm{CH}_{4}$ on all studied $\mathrm{MoC}_{\mathrm{y}} / \mathrm{Au}(111)$ systems. $\mathrm{Au}, \mathrm{Mo}, \mathrm{C}$, and $\mathrm{H}$ atoms are shown as yellow, blue, black, and white spheres, respectively. In all cases, the most stable isomer has been studied, except for the $\mathrm{Mo}_{6} \mathrm{C}_{6}$, where the second most table structure was also studied $\left(\mathrm{Mo}_{6} \mathrm{C}_{6}-2\right)$.

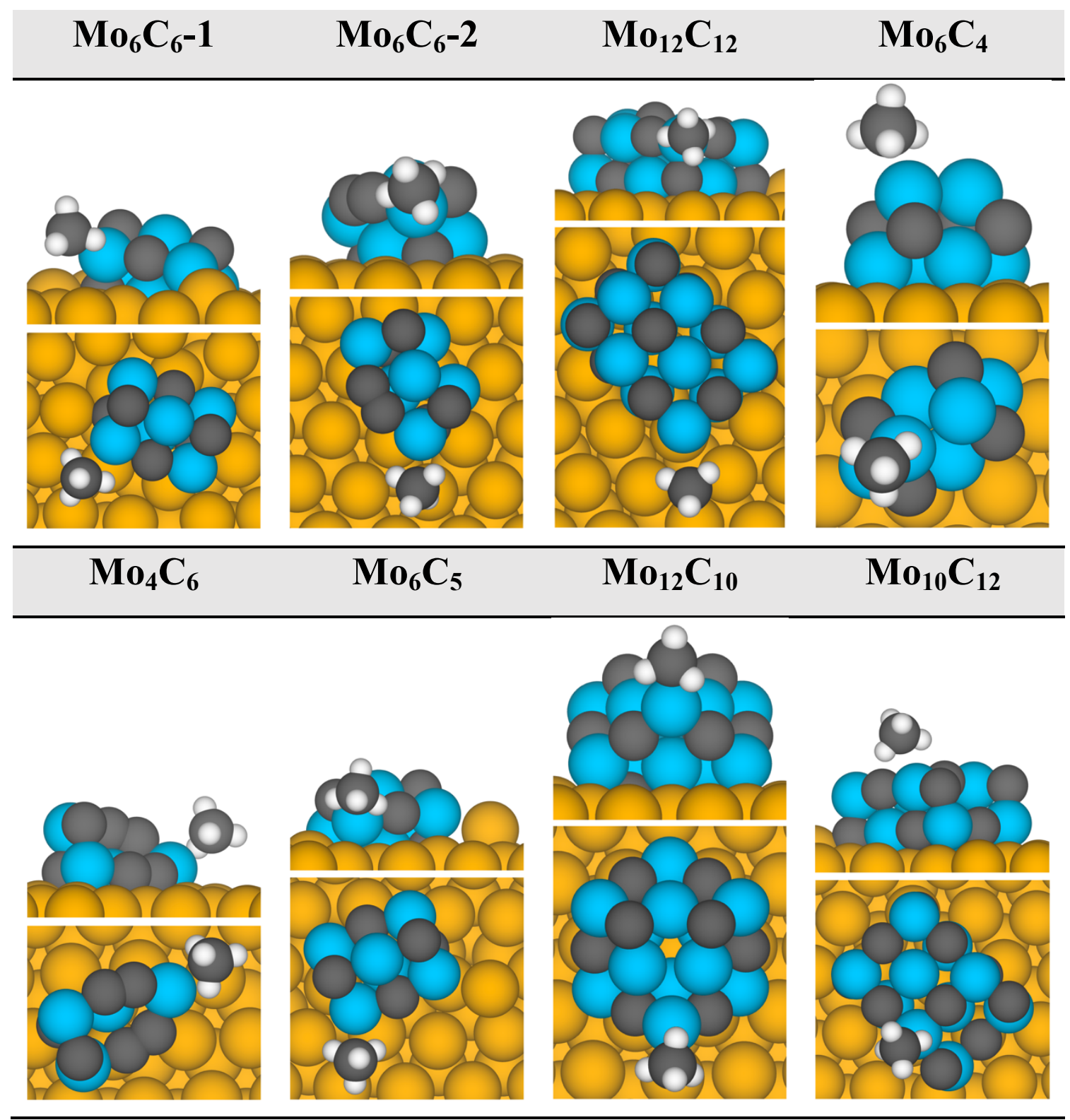


Figure 10. Optimized geometries (top and side views) for the adsorption of methane on $\delta$-MoC(001) and $\mathrm{C} / \mathrm{Mo}$-terminated $\beta-\mathrm{Mo}_{2} \mathrm{C}(0001)$ surfaces. Colour code as in Figure $\mathrm{S} 1$.

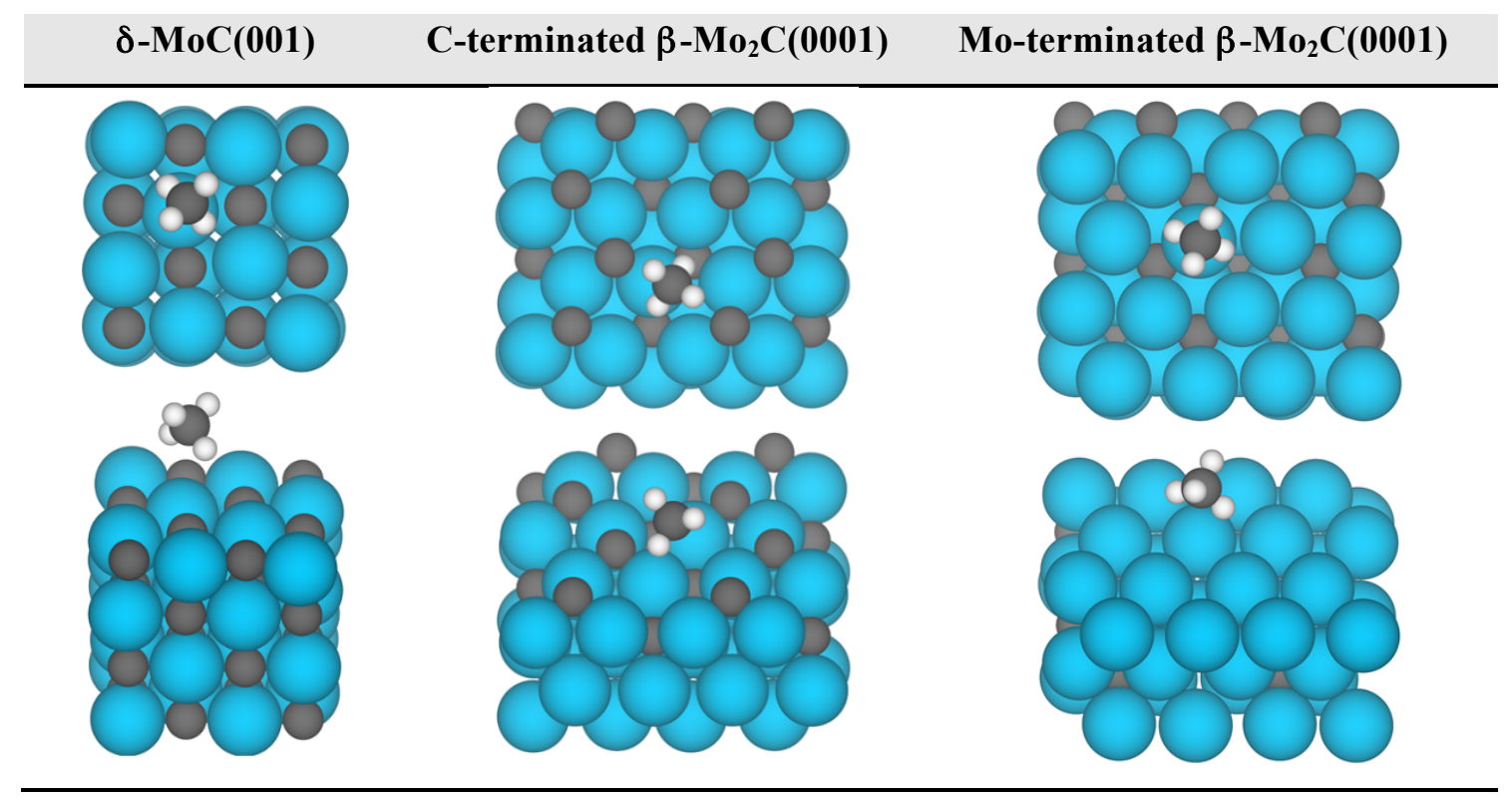


Table 1. Methane adsorption energies $\left(E_{a d s}\right)$ and energy barriers $\left(E_{b}\right)$ and reaction energies $\left(E_{\text {reac }}\right)$ for $\mathrm{CH}_{4}$ dissociation on all studied systems.

\begin{tabular}{llll} 
System & $E_{a d s}(\mathrm{eV})$ & $\mathrm{E}_{\mathrm{b}}(\mathrm{eV})$ & $\mathrm{E}_{\text {reac }}(\mathrm{eV})$ \\
\hline $\mathrm{Mo}_{6} \mathrm{C}_{6}-1$ & -1.16 & 0.58 & -0.68 \\
$\mathrm{Mo}_{6} \mathrm{C}_{6}-2$ & -0.95 & 1.02 & -0.79 \\
$\mathrm{Mo}_{12} \mathrm{C}_{12}$ & -0.61 & 0.60 & -0.33 \\
$\mathrm{Mo}_{6} \mathrm{C}_{4}$ & -0.48 & 0.08 & -1.98 \\
$\mathrm{Mo}_{4} \mathrm{C}_{6}$ & -0.38 & 0.63 & -1.03 \\
$\mathrm{Mo}_{6} \mathrm{C}_{5}$ & -0.45 & 0.58 & -0.55 \\
$\mathrm{Mo}_{12} \mathrm{C}_{10}$ & -0.51 & 0.37 & -0.62 \\
$\mathrm{Mo}_{10} \mathrm{C}_{12}$ & -0.22 & 0.58 & -1.57 \\
$\delta$-MoC $(001)$ & -0.17 & 1.20 & 0.59 \\
$\mathrm{C}$-terminated $\beta-\mathrm{Mo}_{2} \mathrm{C}(0001)$ & -0.18 & 0.67 & -0.66 \\
Mo-terminated $\beta-\mathrm{Mo}_{2} \mathrm{C}(0001)$ & -0.39 & 0.48 & -1.66 \\
\hline
\end{tabular}


Figure 11. Energy barrier $\left(\mathrm{E}_{\mathrm{b}}\right)$ for $\mathrm{CH}_{4}$ to $\mathrm{CH}_{3}+\mathrm{H}$ dissociation on different molybdenum carbide nanoparticles (black triangles) and extended surfaces (blue dots) versus the reaction energy $\left(\mathrm{E}_{\text {reac }}\right.$ ). The values used to construct the plot are reported in Table 1. The linear regression corresponds to the values from the extended surfaces only.

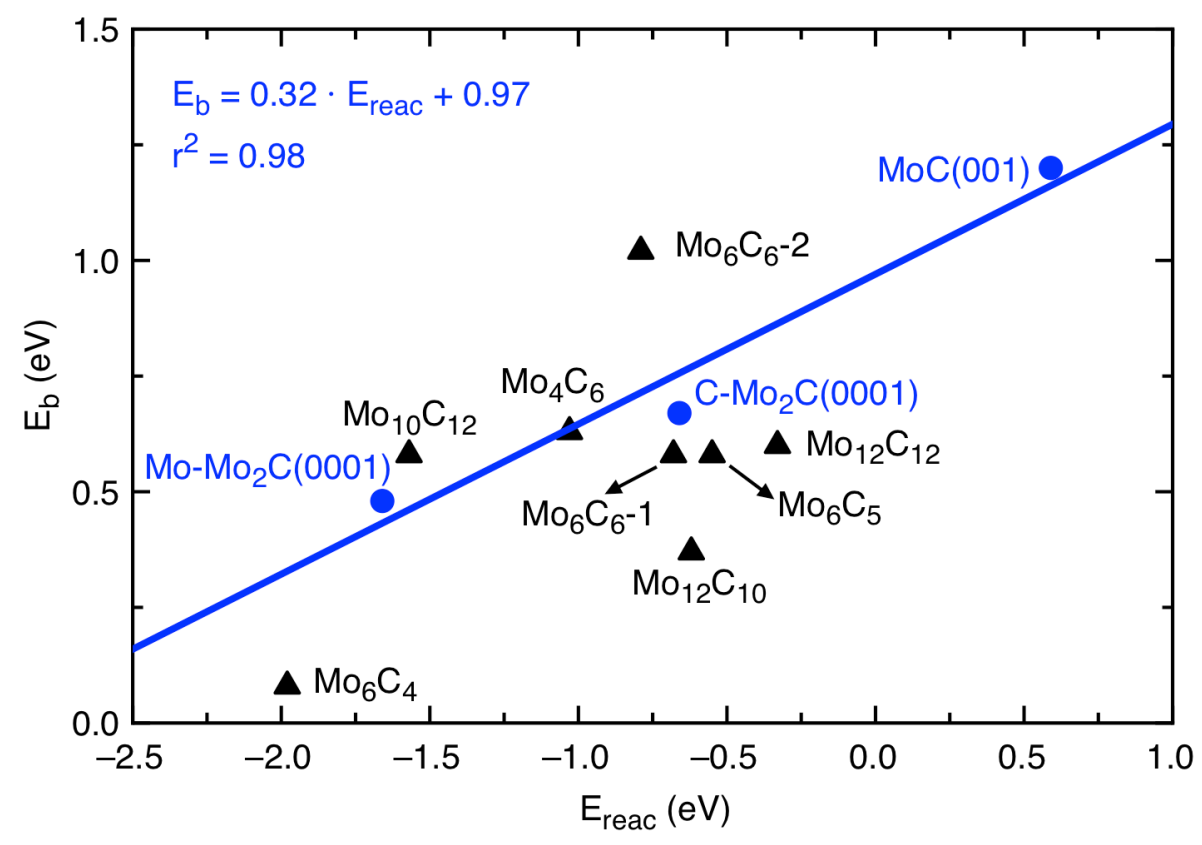




\section{NOTES AND REFERENCES}

${ }^{1}$ P. Tang, Q. Zhu, Z. Wu and D. Ma, Energy Environ. Sci., 2014, 7, 2580-2591.

2 J. Feichter, U. Schurath and R. Zellner, Chem. Unserer Zeit, 2007, 41, 138-150.

${ }^{3}$ D. L. Woodard, S. J. Davis and J. T. Randerson, Proc. Natl. Acad. Sci., 2019, 116, 759-764.

${ }^{4}$ S. I. Chan and S. S. Yu, Acc. Chem. Res., 2008, 41, 969-979.

${ }^{5}$ M. Ravi, V. L. Sushkevich, A. J. Knorpp, M. A. Newton, D. Palagin, A. B. Pinar, M. Ranocchiari and J. A. van Bokhoven, Nature Catal. 2019, 2, 485-494.

${ }^{6}$ P. Khirsariya and R. K. Mewada, Procedia Engineering, 2013, 51, 409-415.

${ }^{7}$ H. Prats, R. A. Gutiérrez, J. J. Piñero, F. Viñes, S. T. Bromley, P. J. Ramírez, J. A. Rodriguez and F. Illas, J. Am. Chem. Soc., 2019, 141, 5303-5313.

${ }^{8}$ T. V. Choudhary, E. Aksoylu and D. W. Goodman, Catal. Rev., 2003, 45, 151-203.

${ }^{9}$ T. P. Jr. Beebe, D. W. Goodman and B. D. Kay, J. Chem. Phys., 1987, 87, 2305-2315.

${ }^{10}$ F. Viñes, Y. Lykhach, T. Staudt, C. Papp, H.-P. Steinrück, J, Libuda, K. M. Neyman and A. Görling, Chem. Eur. J., 2010, 16, 6530-6539.

${ }^{11}$ S. M. Kozlov and K. M. Neyman, J. Catal., 2017, 336, 111-121.

${ }^{12}$ Z. Liang, T. Li, M. Kim, A. Asthagiri and J. F. Weaver, Surface. Science, 2017, 356, 299-303.

${ }^{13}$ Z. Liu, D. G. Grinter, P. G. Lustemberg, T.-D. Nguyen-Phan, Y. Zhou, S. Luo, I. Waluyo, E. J. Crumlin, D. J. Stacchiola, J. Zhou, J. Carrasco, H. F. Busnengo, M. V. Ganduglia-Pirovano, S. D. Senanayake and J. A. Rodriguez, Angew. Chem. Int. Ed., 2016, 55, 7455-7459.

${ }^{14}$ P. G. Lustemberg, P. J. Ramírez, Z. Liu, R. A. Gutiérrez, D. G. Grinter, J. Carrasco, S. D. Senanayake, J. A. Rodriguez and M. V. Ganduglia-Pirovano, ACS Catal., 2016, 6, 8184-8191.

${ }^{15}$ H. F. Li, Z.-Y. Li, Q.-Y. Liu, X.-N. Li, Y.-X. Zhao and S.-G. He, J. Phys. Chem. Lett., 2015, 6, 2287-2291.

${ }^{16}$ F. Solymosi, A. Szöke and J. Cserény, Catal. Lett., 1996, 39, 157-161.

${ }^{17}$ N. K. Razdan, A. Kumar and A. Bhan, J. Catal., 2019, 372, 370-381.

${ }^{18}$ M. Rahman, A. Sridhar and S. J. Khatib, Applied Catal. A: General, 2018, 558, 67-80.

19 S. Posada-Perez, J. R. dos Santos Politi, F. Viñes and F. Illas, RSC Advances, 2015, 5, 3373733746.

${ }^{20}$ T. Zhang, X. Yang and Q. Ge, Catal. Today, 2019, DOI: 10.1016/j.cattod.2019.03.020

${ }^{21}$ W. Ding, S. Li, G. D. Meitner and E. Iglesia, J. Phys. Chem. B, 2001, 105, 506-513.

22 J. M. Horn, Z. Song, D. V. Potapenko, J. Hrbek and M. G. White, J. Phys. Chem. B, 2005, 109, 44-47.

${ }^{23}$ V. Pallassana and M. Neurock, J. Catal., 2000, 191, 301-317. 
${ }^{24}$ J. N. Brønsted, Chem. Rev. 1928, 5, 231-338.

${ }^{25}$ M. G. Evans and M. Polanyi, Trans. Faraday Soc., 1938, 34, 11-24.

${ }^{26}$ T. Cai, Z. Song, J. A. Rodriguez and J. Hrbek, J. Am. Chem. Soc., 2004, 126, 8886-8887

${ }^{27}$ J. A. Rodriguez and J. Hrbek, Surf. Sci., 2010, 604, 241-244

${ }^{28}$ J. A. Rodriguez, P. Liu, J. Graciani, S. D. Senanayake, D. C. Grinter, D. Stacchiola, J.Hrbek and J. Fernandez-Sanz, J. Phys. Chem. Lett., 2016, 7, 2627-2639

${ }^{29}$ J. Kang, M. Mahapatra, N. Rui, I. Orozco, R. Shi, S. D. Senanayake and J. A. Rodriguez, J. Chem. Phys., 2020, 152, 054702

${ }^{30}$ Z. Song, T. Cai, J. A. Rodriguez, J. Hrbek, A. S. Y. Chan and C. M. Friend, J. Phys. Chem. B, 2003, 107, 1036-1043

${ }^{31}$ P. Reinke and P. Oelhafen, Surf. Sci., 2000, 468, 203-215.

32 J. A. Rodriguez, J. Dvorak and T. Jirsak, Surf. Sci., 2000, 457, L413-L420.

${ }^{33}$ T. P. St. Clair, T. Oyama, D. F. Cox, S. Otan, Y. Ishizawa, R. L. Lo, K. Fukui and Y. Iwasawa, Surf. Sci., 1999, 426, 187-198.

${ }^{34}$ S. Posada-Perez, P. J. Ramirez, J. Evans, F. Viñes, P. Liu, F. Illas and J. A. Rodriguez, J. Am. Chem. Soc., 2016, 138, 8269-8278.

35 J .A. Rodriguez, P. Liu, J. Dvorak, T. Jirsak, J. Gomes, Y. Takahashi and K. Nakamura, J. Chem. Phys., 2004, 121, 465-474

${ }^{36}$ F. Frantz and S. V. Didziulis, Surf. Sci,. 1998, 412/413, 384

${ }^{37}$ S. V. Didziulis, P. Frantz, S.S. Perry, O. El-bjeirami, S. Imaduddin, P. B. Merrill, J. Phys. Chem. B, 1999, 103, 11129

${ }^{38}$ J. B. Park, J. Graciani, J. Evans, D. Stacchiola, S. Ma, P. Liu, A. Nambu, J. F. Sanz, J. Hrbek and J. A. Rodriguez, Proc. Natl. Acad. Sci., 2009, 106, 4975-4980.

39 J. A. Rodriguez, P. Liu, J. Hrbek, M. Pérez and J. Evans, J. Mol. Catal. A: Chem., 2008, 281, 5965.

${ }^{40}$ Y. Yang, J. Evans, J. A. Rodriguez, M. G. White and P. Liu, Phys. Chem. Chem. Phys., 2010, 12, 9909-9917.

${ }^{41}$ J. A. Rodriguez, J. Evans, L. Feria, A. B. Vidal, P. Liu, K. Nakamura and F. Illas, J. Catal., 2013, 307, 162-169.

${ }^{42}$ O. Lamiel, S. T. Bromley and F. Illas, Theor. Chem. Acc., 2013, 132, 1312

${ }^{43}$ J. P. Perdew, K. Burke and M. Ernzerhof, Phys. Rev. Lett., 1996, 77, 3865-3868.

44 J. R. d. S. Politi, F. Viñes, J. A. Rodriguez and F. Illas, Phys. Chem. Chem. Phys., 2013, 15, 12617-12625. 
${ }^{45}$ L. Vega, J. Ruvireta, F. Viñes and F. Illas, J. Chem. Theory Comput. 2018, 14, 395-403

${ }^{46}$ S. Grimme, J. Antony, S. Ehrlich and S. A. Krieg, J. Chem. Phys., 2010, 132, 154104.

${ }^{47}$ G. Henkelman, B. P. Uberuaga and H. A. Jónsson, Phys. Rev. B, 2000, 113, 9901-9904.

${ }^{48}$ A. H. Larsen, J. J. Mortensen, J. Blomqvist, I. E. Castelli, R. Christensen, M. Dułak, J. Friis, M. N. Groves, B. Hammer, C. Hargus, E. D. Hermes, P. C. Jennings, P. B. Jensen, J. Kermode, J. R. Kitchin, E. L. Kolsbjerg, J. Kubal, K. Kaasbjerg, S. Lysgaard, J. B. Maronsson, T. Maxson, T. Olsen, L. Pastewka, A. Peterson, C. Rostgaard, J. Schiøtz, O. Schütt, M. K. S. Strange, T. Vegge, L. Vilhelmsen, M. Walter, Z. Zeng and K. W. Jacobsen, J. Phys. Condens. Matter., 2017, 29, 273002.

${ }^{49}$ S. Smidstrup, A. Pedersen, K. Stokbro and H. Jónsson, J. Chem. Phys., 2014, 140, 214106.

${ }^{50}$ G. Kresse and J. Furthmüller, Phys. Rev. B., 1996, 54, 11169-11186.

${ }^{51}$ J. S. Yoo, J. Schumann, F. Studt, F. Abild-Pedersen and J. K. Nørskov, J. Phys. Chem. C, 2018, 122, 16023-16032.

${ }^{52}$ W. Wu, P. J. Ramirez, D. Stacchiola, and J. A. Rodriguez, Catal. Letters, 2014, 144, 1418-1424.

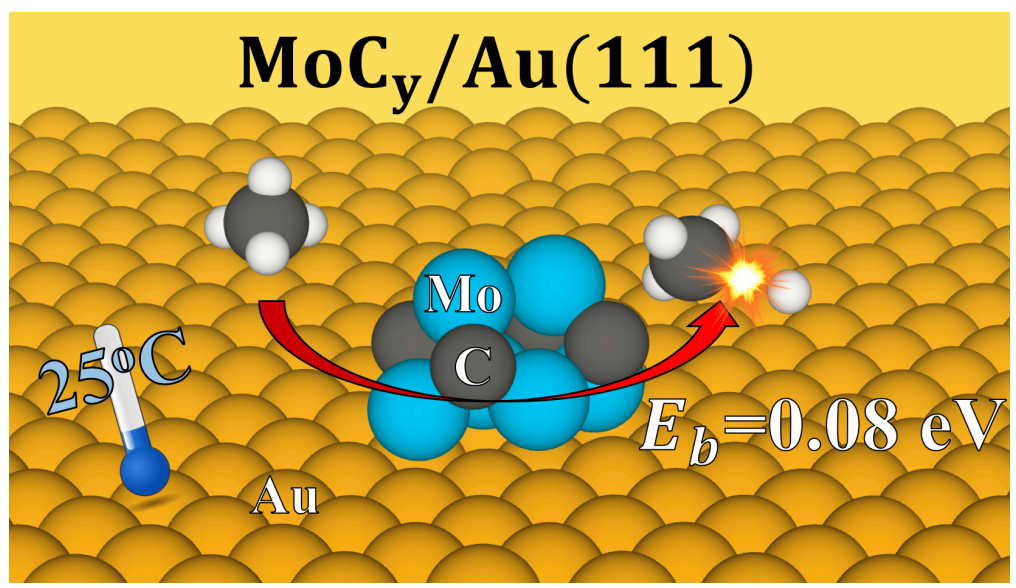

